\title{
Bovine jugular vein thrombosis in the Fontan circulation
}

\author{
Paul H. Schoof, MD, PhD, ${ }^{a}$ Arjun D. Koch, MD, ${ }^{\text {a }}$ Mark G. Hazekamp, MD, PhD, ${ }^{\text {a }}$ Tjalling W. Waterbolk, MD, ${ }^{b}$
}

Tjark Ebels, MD, PhD, ${ }^{\mathrm{b}}$ and Robert A. Dion, $\mathrm{MD},{ }^{\mathrm{a}}$ Leiden and Groningen, The Netherlands

$\mathrm{T}$

he bovine jugular vein (Contegra; Medtronic, Inc, Minneapolis, Minn) is an alternative conduit for reconstruction of the right ventricular outflow tract ${ }^{1}$ that also has potentially attractive characteristics for use in the Fontan circulation. We implanted this newly introduced conduit in 3 patients as an extracardiac connection between the inferior caval vein and the pulmonary artery to complete the cavopulmonary circulation. Their histories are described. All 3 patients had thrombosis develop in the conduit. The mechanism of this complication remains to be elucidated. Two patients died, and the other had

From the Department of Cardiothoracic Surgery, Leiden University Medical Center, Leiden, ${ }^{a}$ and the Department of Cardiothoracic Surgery, Groningen University Medical Center, Groningen, ${ }^{\mathrm{b}}$ The Netherlands.

Received for publication Feb 27, 2002; accepted for publication April 8, 2002.

Address for reprints: Paul H. Schoof, MD, PhD, Department of Cardiothoracic Surgery, K6-S, Leiden University Medical Center, PO Box 9600, 2300 RC Leiden, The Netherlands (E-mail: pschoof@lumc.nl).

J Thorac Cardiovasc Surg 2002;124:1038-40

Copyright $\odot 2002$ by The American Association for Thoracic Surgery

$0022-5223 / 2002 \$ 35.00+0 \quad \mathbf{1 2 / 5 4 / 1 2 5 6 4 6}$

doi: $10.1067 / \mathrm{mtc} .2002 .125646$ neurologic damage. Use of the Contegra conduit in the Fontan circulation is discouraged.

\section{Clinical Summaries}

PATIENT 1. A 7-year-old boy (body weight $20 \mathrm{~kg}$ ) with dextrocardia, right atrial isomerism, unbalanced atrioventricular septal defect, and discordant ventriculoarterial connections underwent a bidirectional cavopulmonary anastomosis after previous pulmonary artery banding. The Fontan circulation was completed with a 20-mm valved segment of bovine jugular vein (Contegra) implanted as an extracardiac conduit between a normal inferior caval vein and the left pulmonary artery. Unobstructed flow through the conduit was confirmed by intraoperative transesophageal echocardiography. Two days later, a 5-mm fenestration between the conduit and the atrium was created because of low cardiac output and a high systemic venous pressure. Warfarin sodium was given as antithrombotic prophylaxis, and the patient was discharged on day 9. Six months later, surgical reopening of the spontaneously closed fenestration was planned because of unexplained protein-losing enteropathy and progressive dyspnea on exertion. However, the patient required urgent admission following discontinuation of the anticoagulants because of evolving cardiac shock. Transthoracic echocardiography revealed obstruction of the bovine conduit. Immediate surgical revision was carried out, and a subtotal thrombotic occlusion of the conduit was found (Figures 1 and 2). 


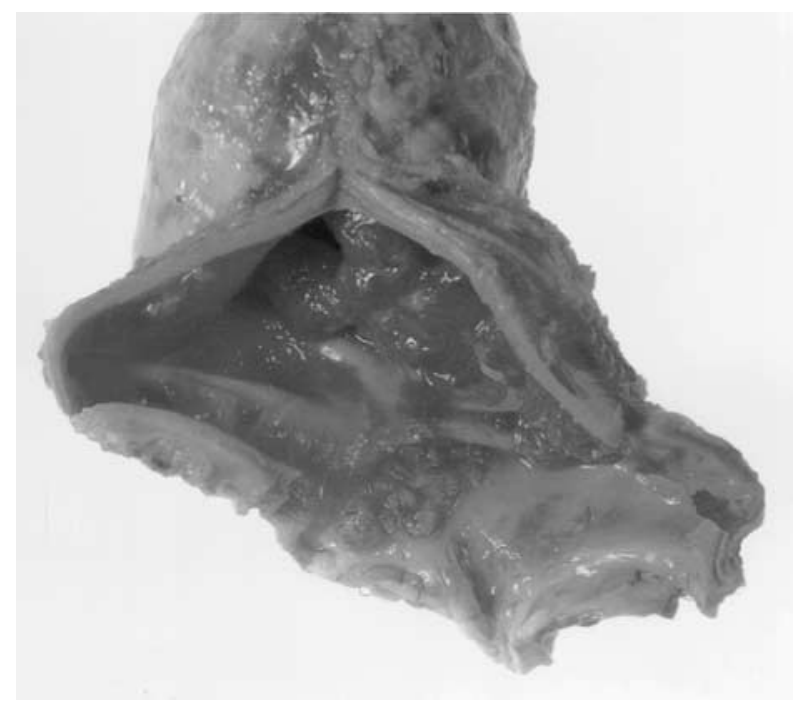

Figure 1. Explanted bovine jugular venous conduit opened longitudinally to show mural thrombi and occlusive thrombotic mass.

The bovine jugular conduit was replaced with a 20 -mm fenestrated polytetrafluoroethylene*1 (PTFE) conduit. Microscopy confirmed that occlusion of the conduit was caused by thrombosis. Although the absence of cellular ingrowth into the thrombus prevented assessment of the exact age of the thrombus, its structure indicated that its formation had evolved during a period of weeks. The patient was extubated 10 days after the operation and anticoagulants were resumed, but an acceptable international normalized ratio was difficult to attain because of hepatic and renal dysfunction. Three weeks later, the patient died during surgical evacuation of a cerebral hemorrhage.

PATIENT 2. A 3-year-old boy $(12.5 \mathrm{~kg})$ with tricuspid atresia, concordant ventriculoarterial connections, and restrictive ventricular septal defect had a previous modified right Blalock-Taussig shunt followed by a bidirectional cavopulmonary anastomosis. He underwent a total cavopulmonary connection created with a 14-mm valveless segment of bovine jugular vein as an extracardiac conduit. A fenestration was created between the conduit and the atrium. Unobstructed flow through the conduit was confirmed by intraoperative transesophageal echocardiography. No anticoagulants were given after the operation. Seven days later, symptoms of discomfort and nausea preceded cyanosis and was followed by a state of shock. Transthoracic echocardiography during resuscitation provided no information on conduit patency. Cardiopulmonary resuscitation including external cardiac massage was unsuccessful. During resuscitation cyanosis persisted. At autopsy, large thrombi were found to occlude both the right and left pulmonary arteries, and thrombotic material was found adherent to the luminal side of the conduit near the fenestration. On the basis of microscopy of the pulmonary thrombi, which showed focal organization, the age of the thrombi was estimated to be 1 to 2 days. No thrombi were found in the peripheral pulmonary arteries.

*Gore-Tex Stretch Vascular Graft, registered trademark of W. L. Gore \& Associates, Inc, Flagstaff, Ariz.

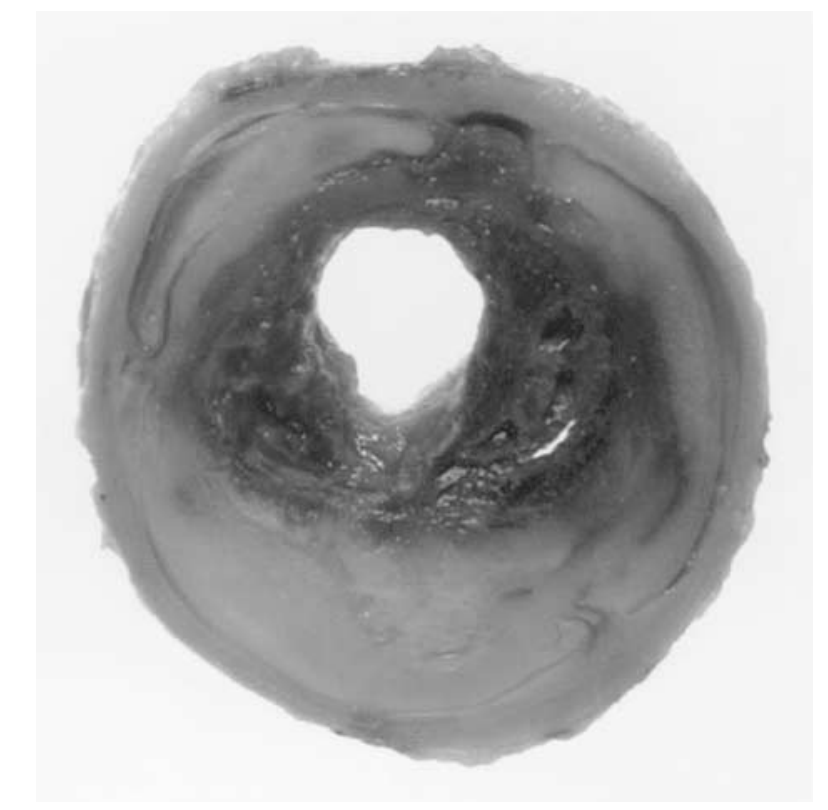

Figure 2. Transverse section of specimen shows densely organized thrombus adjacent to conduit wall and fresh thrombus in center.

PATIENT 3. A 3-year-old boy (14 kg) with tricuspid atresia, concordant ventriculoarterial connections, and pulmonary stenosis underwent creation of a Blalock-Taussig shunt followed by a bidirectional cavopulmonary anastomosis. The total cavopulmonary connection was completed with an 18-mm valveless segment of bovine jugular vein as an extracardiac conduit. A fenestration was created between the conduit and the atrium. Unobstructed flow through the conduit was confirmed echocardiographically. A few hours after the patient's arrival in the intensive care unit, low cardiac output developed, associated with high systemic venous pressures and cyanosis. Transthoracic echocardiography 5 hours after the operation raised the suspicion of conduit obstruction. At surgical revision, a subtotal occlusion of the conduit was found, with the thrombus localized halfway through the prosthesis near the fenestration.

A 16-mm PTFE conduit was used to replace the bovine conduit. During postoperative recovery, a left-sided hemiparesis with aphasia and ataxia developed as a result of a parietal cerebral infarction diagnosed on computed tomographic scan. At the latest follow-up, minor left-sided hypertonia and facial paresis persisted.

\section{Discussion}

The use of the Contegra bovine jugular venous conduit for the final stage Fontan operation is a conceivable step for the surgeon accustomed to and satisfied with this conduit for reconstruction of the right ventricular outflow tract. This step was made independently in our country by two surgeons from two different institutions, both of whom saw the same adverse outcome. Thrombosis occurred in 1 patient who received antithrombotic prophylaxis. It probably took weeks to evolve and started to cause symptoms when the prophylaxis was stopped. In the second patient, who had no antithrombotic prophylaxis, similar symptoms developed as 
early as 7 days after the operation. Although most of the thrombotic fragments were found in the large pulmonary arteries, the observation of thrombotic deposits on the inner surface of the conduit, the age of the thrombus (1 to 2 days), and the fact that external heart massage had been applied led us to believe that the conduit was the original source. In the third patient, the conduit obstruction developed only a few hours after the operation. Because a peripheral source of thromboemboli is unlikely so early after the operation, thrombus formation in the conduit is the most plausible explanation. The unilateral cerebral infarction may be attributed to a paradoxical thromboembolus through the fenestration.

In all 3 cases, the conduit fenestration may have played a role in the origin of the thrombosis as a result of focally disturbed flow patterns. Indeed, thrombus deposition was found near the fenestration in both patients with a patent fenestration and was incorporating the site of the occluded fenestration in the first patient. The valve of the conduit, which was found to be included within the thrombus in the first patient, may also have been a site at risk for thrombus formation.

We treated 23 other patients who were comparable in terms of age, use of antithrombotic prophylaxis, and fenestration and who also underwent a total cavopulmonary connection but with the use of PTFE as an extracardiac conduit. Thrombosis did not occur in any of these patients. The difference between no thrombotic events in 23 patients $(0 \%, 95 \%$ confidence interval $0 \%-15 \%)$ and 3 thrombotic events in 3 patients $(100 \%$, 95\% confidence interval $29 \%-100 \%)$ in whom the bovine jugular vein was used is statistically significant $(P<.001$ by the Fisher exact test). There have been no reports in the literature of conduit obstruction in the Fontan circulation as a result of extensive thrombosis in properly sized extracardiac conduits, ${ }^{2-5}$ so the major cause of thrombosis must be related to the nature of the jugular bovine conduit itself, associated with the local conditions of blood flow.

Pathologic data on prosthetic conduits used for extracardiac construction of a total cavopulmonary connection do not exist. Other prosthetic conduits, such as Dacron polyester fabric and PTFE, and arterial allografts acquire a "neointima" after implantation in the arterial circulation, which effectively establishes a host-to-tissue compatibility that is important to prevent thrombosis. ${ }^{6-8}$ A protective host endothelial coverage was absent in bovine jugular venous explants after 6 months in the pulmonary position in mongrel dogs. Explants instead showed an inflammatory reaction in both the valve and the wall of the conduit, which was associated with cuspal thrombus in 1 of the studied cases. ${ }^{9}$ This lack of endothelial resurfacing and the inflammatory response, both of which were attributed to the cytotoxicity of the applied cross-linking agent glutaraldehyde, may explain the increased tendency for thrombosis. In addition, the surface of this cytotoxic area is large in the bovine jugular venous conduit relative to other bioprosthetic valves, which may further add to thrombogenicity. Both factors may be of limited importance in the high pulsatile flow of the right ventricular outflow tract but could become critical when flow is slow and nonpulsatile. If the cross-linking agent glutaraldehyde is the cause of the observed thrombogenicity, replacing it with a less cytotoxic agent might allow increased biocompatibility and endothelialization, with reduced thrombogenicity.

\section{Conclusion}

Obstructive thrombosis may occur in the Contegra bovine jugular venous conduit used as an extracardiac conduit in the Fontan circulation. We discourage the use of this conduit for this indication.

\section{References}

1. Breymann T, Thies W, Blanz U, Boethig D, Goerg R, Koertke H. RVOT-reconstruction with bovine valved jugular veins as an alternative to homografts and porcine xenografts (abstract). Circulation. 2001;104(Suppl):II-644.

2. Tokunaga S, Kado H, Imoto Y, Masuda M, Shiokawa Y, Fukae K, et al. Total cavopulmonary connection with an extracardiac conduit: experience with 100 patients. Ann Thorac Surg. 2002;73:76-80.

3. Amodeo A, Galetti L, Marianeschi S, Picardo S, Giannico S, Di Renzi P, et al. Extracardiac Fontan operation for complex cardiac anomalies: seven years' experience. J Thorac Cardiovasc Surg. 1997;114:1020-31.

4. Petrossian E, Reddy VM, McElhinney DB, Akkersdijk GP, Moore P, Parry AJ, et al. Early results of the extracardiac conduit Fontan operation. J Thorac Cardiovasc Surg. 1999;117:688-96.

5. Haas G, Hess H, Black M, Onnasch J, Mohr F, van Son J. Extracardiac conduit Fontan procedure: early and intermediate results. Eur J Cardiothorac Surg. 2000;17:648-54.

6. Pasquinelli G, Freyrie A, Preda P, Curti T, D'Addato M, Laschi R. Healing of prosthetic arterial grafts. Scanning Microsc. 1990;4:35162.

7. Marios Y, Wagner E, Pâris E, Roy R, Douville Y, Guidoin R. Comparison of healing in fresh and preserved arterial allografts in the dog. Ann Vasc Surg. 1999;13:130-40.

8. Bordenhave L, Remy-Zolghadri M, Fernandez P, Bareille R, Midy D. Clinical performance of vascular grafts lined with endothelial cells. Endothelium. 1999;6:267-75.

9. Chang Y, Tsai CC, Liang HC, Sung HW. Reconstruction of the right ventricular outflow tract with a bovine jugular vein graft fixed with a naturally occurring crosslinking agent (genipin) in a canine model. J Thorac Cardiovasc Surg. 2001;122:1208-18. 